\title{
Television Newsmagazine Coverage of Child Sexual Abuse: 1990-2005
}

Yael Shavit' ${ }^{1}$, Aaron Q Weinstein ${ }^{2}$, Zachary Reiss-Davis ${ }^{3}$ and Ross E Cheit ${ }^{4 *}$

${ }^{1}$ Law and San Francisco Affirmative Litigation Project Fellow, Yale University Law School

${ }^{2} P h . D$. in Political Science, Brown University

${ }^{3}$ Department of Product Marketing, Salesforce.com

${ }^{4}$ Department of Public Policy and Political Science, Brown University, USA

\begin{abstract}
Objective: There were two aims: first, to analyze trends in television newsmagazines coverage of child sexual assault (CSA) between 1990 and 2005; and second, to offer comparisons between this study and our previous work on e newsmagazines CSA coverage.

Method: A database was created to identify all relevant CSA stories appearing in seven primetime television newsmagazines. The study employs systematic analysis of segments by subject, length, and individual anchoring each broadcast.

Results: The results affirm established theories of CSA media coverage. Television segments contain an average of three newsworthiness factors, which is more than was found of print newsmagazines. Findings also show differences in slant between the top three anchors (Dan Rather, Stone Phillips, and Barbara Walters), indicating significant editorial control in newsmagazines CSA coverage. Finally, this study shows that television newsmagazines offer more polarized coverage than print newsmagazines, and on different subjects (i.e. focusing on Michael Jackson, whereas print focuses on the Church sex abuse cover-up story).

Conclusions: Television newsmagazines offer skewed coverage of CSA. Like other media, they focus on "newsworthy" stories ("stranger-danger") rather than the most prevalent forms of CSA (intra-familial abuse). Given that this newsmagazines coverage is more polarized than print, however, we suggest that this coverage may have real impacts upon public policy and its implementation.
\end{abstract}

Keywords: Catholic Church; Child sexual abuse; Media; Michael Jackson; Newsworthiness; Slant; Television

\section{Introduction}

The ways in which news media address important social issues can substantially affect how people perceive and respond to these phenomena. Child sexual abuse (CSA) is a pervasive social problem: a recent meta-analysis of surveys in the United States indicates that between 1969 and 1991, 22.3\% of females and 8.5\% of males report experiencing sexual abuse as children [1]. And like other violent crimes, it is particularly susceptible to public misperception. Past studies demonstrate that news media give disproportionate attention to unusual CSA stories, running the risk of skewing public perception. Given the extent to which public opinion can affect public policy, it is important for researchers to understand how the news media present information about childhood sexual abuse. Yet there has been surprisingly little research performed to help understand general media coverage over time.

The present study is a follow-up of Cheit et al.'s [2] analysis of trends in print newsmagazines coverage of CSA between 1992 and 2004. We undertook this analysis to ascertain how television newsmagazines cover CSA incidents during the period between 1990 and 2005, and to see what similarities and differences exist between CSA coverage in print and visual media. This study was designed to create a replicable methodology that will allow researchers to study CSA coverage by other media outlets and in future time periods.

\section{Literature Review}

People cannot possibly take in all of the complexities of the real world [3]. Much of what Americans know about the world, therefore, is gathered from second-hand sources: in particular, the news media. Shanto Iyengar [4] calls the media the public's "mind's eye," in that they set the agenda and tenor of public discourse (see also Iyengar and Kinder, McCombs and Reynolds, and Scheufel and Tewksbury [57]. This gives journalists, editors, and anchors considerable influence over how Americans perceive reality. And in light of this power it is important to underscore that the media are far from unbiased relators of information: they operate according to journalistic ethics and norms [8], as well as perceived competition for readership [9]. This phenomenon is evident in crime reporting, where media portrayals of criminal activities differ substantially from actual incidences of crime [10]. And while we do not know how many cases go unreported, scholars agree that official reports underestimate the extent of abuse $[11,12]$, and it is usually the spectacular cases like the Penn State or the Catholic sex abuse cover-ups that attract substantial media attention. Realizing that most Americans understand CSA through the media, it is vital to comprehend the metrics by which media decide which CSA stories are "newsworthy" and which are not.

\section{Newsworthiness}

What does it mean for a crime to be newsworthy? In a basic sense, something is newsworthy when it is out of the ordinary. As Lichtenberg and MacLean [13] remind us, "A newspaper that produced even a representative slice of reality would be exceedingly

*Corresponding author: Ross E Cheit, Professor of Public Policy and Politica Science Brown University, USA, Tel: 863-3523; E-mail: ross_cheit@brown.edu

Received February 27, 2014; Accepted May 22, 2014; Published May 31, 2014

Citation: Shavit Y, Weinstein AQ, Reiss-Davis Z, Cheit RE (2014) Television Newsmagazines Coverage of Child Sexual Abuse: 1990-2005. J Mass Communicat Journalism 4: 196. doi:10.4172/2165-7912.1000196

Copyright: (C) 2014 Shavit Y, et al. This is an open-access article distributed under the terms of the Creative Commons Attribution License, which permits unrestricted use, distribution, and reproduction in any medium, provided the original author and source are credited. 
dull." Newsworthiness is a journalistic norm encapsulated by the New York Times's logan: all the news that's fit to print. It is not news when a dog bites a man-but the reverse absolutely is [14]. Research on crime reporting embraces this premise of "unique" events, and identifies numerous hallmarks of newsworthiness. Crimes are more likely to be reported when they involve serious injury, as well as sentimental or dramatic elements [15]. Characteristics of victims and the accused also factor in: celebrities garner more attention than non-celebrities [1517], as do those who are more cooperative and photogenic [18].

Many scholars, both in crime reporting and media studies, suggest that this attention to newsworthiness leads the media to overemphasize some crimes and deemphasize others. One reason for this is that socalled newsworthy stories fit the media's preference for "episodic" rather than "thematic" news stories. Journalists, particularly crime reporters, have a tendency to focus upon discrete cases because they are easier to sell as stories instead of focusing on overarching themes, which are more difficult. In other words they highlight specific incidents of crime rather than crime as a phenomenon. This tendency-along with their focus upon dramatic stories-can lead viewers to attribute blame to individual victims and perpetrators "rather than to the broad societal forces" [4]. More generally, it means that the media portray rare crimes as both more common and more unpredictable than they may actually be $[19,20]$. Pirkis et al. [21] show that suicides are more likely to be reported when they contain characteristics like "celebrity status" or "unusual methods." And Lawrence and Mueller [14] demonstrate the media depict school shootings as an imminent threat, even though less than $1 \%$ of homicides or suicides of school-age children happen at, on the way to, or near school.

The issue of newsworthiness is especially important in studies of CSA because, as Skidmore [22] concludes, "CSA stories are often produced within [this] framework of newsworthiness associated with the coverage of crime and deviance." And as with other incidents of crime, few Americans (though more than should) have first-hand experience with CSA [2,23-26]. The media produce news that showcases real-life drama, and few stories can draw more sympathy than the abuse of a child. As other recent CSA studies indicate, reporting emphasizes the newsworthiness of individual cases and instances of abuse, often taking the form of child abuse horror stories [27,28]. Cheit [23] finds several determinants of CSA newsworthiness: cases involving firstdegree charges, multiple counts, additional violence, or multiple victims were all more likely to receive coverage; and that newspaper coverage over-represents the rare instances of "stranger danger" while under-representing more common instances of intra-familial abuse. So while CSA cases like Jerry Sandusky at Penn State or the Catholic sexual abuse cover-up are indeed horrifying, the media's fixation upon these cases paints a distorted picture of reality for the American public.

\section{Print Newsmagazines Study (2010)}

As the present study builds upon Cheit et al's [2] print newsmagazines analysis, it is important to briefly outline some results and conclusions from our previous study. This not only sets the stage for the present study, it permits this article to draw parallels-and highlight differences-between the print and visual media.

Cheit et al. [2] analyzes four print newsmagazines-Time, Newsweek, U.S. News and World Report, and People Magazine-to understand how this particular medium covers CSA stories. In all, these four print newsmagazines produced 172 stories about this topic between 1992 and 2004. There were two spikes in coverage: one was moderate (1993), and at the height of the "false memory" era noted by Beckett [29]; and one was significant (2002), driven by stories on the Catholic Church's cover-up of abuse by priests. It is interesting to note, however, that we found no overall trend in the number of CSA stories printed in these newsmagazines. Similarly, there was no relevant pattern in article length, with U.S. News and World Report averaging slightly less than 1000 words per story and the other three newsmagazines averaging close to 1200 .

The rest of the study's findings bolster past research on CSA. For instance, stories addressing specific subjects, like the Catholic Church, spiked as the media began focusing upon these events, only to drop off in subsequent years. This supports the idea that stories are selected based on "salience" with prior news themes [30]. Remarkably, the study also finds evidence that issue slant-the degree to which stories support the victim or accused-does not vary cyclically, as Beckett [29] suggests that it will. Rather, CSA coverage goes through peaks and valleys, where low-discussion years (and therefore low-N's) artificially overemphasize changes in slant. For this reason, even though the overall pro-victim slant during the 13 years we studied is punctuated by two years of "pro-accused" and two of "neutral" coverage, we could not deduce any overall shifts in slant from these data. The past study further underscores that slant arises as a function of the episodic nature of news [4] where every new story presents a new set of facts, complete with new victims and accusers, and consequently new reactionsmaking it difficult for the public to link discrete cases together into broad patterns of abuse. In the previous study we suggested that these findings "are not encouraging": newsworthy factors like scandal and celebrity involvement lead print newsmagazines to overemphasize discrete instances of "stranger danger" and under-emphasize the systematic and far more prevalent patterns of intra-familial abuse.

The current study builds upon Cheit et al. [2] in several important ways. To begin, by examining television newsmagazines rather than print it addresses one limitation of the previous study: the decreased importance of print media as a news source. Quoting an expert on the media, the Pew Project for Excellence in Journalism asserts that, "in the mid 1990's, the news divisions were a prime-time production warhorse for the broadcast networks," a prominence which lasted into the 2000's [31]. Given that our period of inquiry spans the 1990s, television newsmagazines are an appropriate focus of study. In addition, research suggests that the medium through which messages are delivered contributes to how they are received $[4,32,33]$. We have reason to suspect that medium will affect conclusions in CSA media studies, as well. As Kitzinger [25] argues in her work on child sexual abuse, "the range of media included" in a survey of stories will probably affect the findings and conclusions. And finally, this study furthers Cheit et al's [2] aim of implementing the past methodology to investigate CSA coverage by other media.

\section{Method, Data, and Variables}

The goal of the present study is to understand how television newsmagazines cover CSA, and to do so in a manner that allows us to compare these findings with Cheit et al's [2] study of print newsmagazines CSA coverage. In the 2010 study, we found that CSA print media coverage was largely consistent with certain crime reporting theories. We are interested in testing the same hypotheses for television coverage of CSA. To facilitate comparison with the previous study, we elected to examine (nearly) the same time period: from 1990 to 2005. This fifteen-year timeframe also provides us with a substantial amount of data, allowing analyses of trends over time. The current study examines CSA segments aired on seven primetime television 
newsmagazines: Sixty Minutes, Sixty Minutes II, 48 Hours, 20/20, Dateline, Primetime, and Turning Point. We identified and obtained stories by using keyword search in LexisNexis, Factiva, and Burrell's services for "child molestation and sex," and "sexual abuse and child."

\section{Data}

The relevant segments obtained with this search methodology were coded for relevancy using an integer variable from one to four. We scored any segment a "one" if it was unclear why the full-text search returned that result, and it was subsequently discarded. Any segment that mentioned CSA in only a peripheral manner was scored "2," and was similarly not included in our final analysis. Only segments that were scored " 3 " (primarily) or " 4 " (exclusively) about CSA were retained in our dataset. This left us with 248 segments. The few segments that were repeated were kept rather than discarded because we believe viewers perceived these repetitions as an indication that the story was important. For a list of stories repeated, please the see (Appendix 1).

The reviewers participating in coding were undergraduates at Brown University. Ratings were made qualitatively, not through computer software. Prior to evaluating transcripts, these individuals were asked

\begin{tabular}{|l|l|}
\hline Upstanding Accused & $\begin{array}{l}\text { The accused is an upstanding member of his or her } \\
\text { community (e.g. a politician, teacher, or coach) }\end{array}$ \\
\hline Extra Violence & $\begin{array}{l}\text { More violence than normal in child abuse stories is } \\
\text { present }\end{array}$ \\
\hline Multiple Parties & $\begin{array}{l}\text { There are especially strange or memorable facts in the } \\
\text { story (e.g. Satan worship) }\end{array}$ \\
\hline Cover-up & There is an element of a cover-up to the story \\
\hline Celebrity Status & $\begin{array}{l}\text { The victim, the accused, or both are celebrities for } \\
\text { something other than the case (e.g. Michael Jackson) }\end{array}$ \\
\hline Source: Cheit et al. [2] & \\
\hline \multicolumn{2}{|c|}{ Table 1: } \\
\hline \multicolumn{2}{|c|}{ Definitions of CSA Newsworthiness Factors. } \\
\hline
\end{tabular}

\begin{tabular}{|l|l|}
\hline 2010 Study (Print) & 2014 Study (Television) \\
\hline Bad Samaritan & Bad Samaritan \\
\hline Catholic Church & Catholic Church \\
\hline Celebrities & Celebrities \\
\hline Cover-up in Catholic Church & Child Custody \\
\hline Cult & Cover-up in Catholic Church \\
\hline Famous Cases & Cult \\
\hline Incest & False Accusations \\
\hline Internet & Famous Cases \\
\hline Media & Incest \\
\hline Michael Jackson & Internet \\
\hline Minor Consent & Legal Response \\
\hline Miscellaneous & \\
\hline & Michael Jackson \\
\hline Parricide & \\
\hline Policy Solutions & Miscellaneous \\
\hline Psychology & Parricide \\
\hline Religious, not Catholic & Murder \\
\hline School & \\
\hline Sex Trade & Psychology \\
\hline System Failure & Religious, not Catholic \\
\hline Total: 19 & Running Away \\
\hline Mean Slant: 0.46 Mean Slant: 0.40 & School \\
\hline & System Failure \\
\hline & Total 20 \\
\hline
\end{tabular}

Table 2: Television and Print Newsmagazine Subject Taxonomy.

\begin{tabular}{|l|l|}
\hline $\begin{array}{l}\text { Television Newsmagazine Regression } \\
\text { Equation }\end{array}$ & $\begin{array}{l}\text { Print Newsmagazine Regression } \\
\text { Equation }\end{array}$ \\
\hline $\begin{array}{l}y=0.85 x+8.3 \\
r^{2}=0.38\end{array}$ & $\begin{array}{l}y=0.66 x+7.3 \\
r^{2}=0.067\end{array}$ \\
\hline
\end{tabular}

Table 3: Television Newsmagazine and Print Newsmagazine Regression Equations.

by the study's designers to review twenty controlled transcripts, which were used to normalize the ratings and ensure consistency. During this training process, any borderline cases-those on which raters had differing interpretations-were discussed to ensure all reviewers handled cases similarly. This is the same way we addressed inter-rater reliability in the 2010 study, and here again attained 95\% agreement between raters on whether or not to include a segment. The reviewers were not blind to the newsmagazines from which each segment was taken. And finally, all reviewers were previously unfamiliar with scholarly work on CSA and therefore did not harbor any inherent biases regarding the manner in which these newsmagazines may treat the subject.

\section{Variables}

The present study reproduces the same variables examined in Cheit et al. [2]: the subject of each CSA story, the presence or absence of specific newsworthiness factors, and the overall slant of quotations.

We coded stories for subject in order to determine which issues are most widely written about, whether different publications cover different subjects, and whether certain subjects were favored during specific years. In an effort to facilitate comparisons between this study and the 2010 study, we used the same broad taxonomy employed previously. For instance, we include categories to account for "coverup in Catholic Church," "celebrities," "Michael Jackson," "school," and others. For those segments that did not clearly fit under previous headings, new subject headers were created. It is worth noting that some modifications were made: for a full list of categories, as well as differences between the 2010 and 2014 studies (Tables 1 and 2). All in all this process resulted in twenty subject categories for the present study, including a miscellaneous category for the twenty segments that did not fit any of the other subjects.

Again continuing the coding scheme from Cheit et al. [2], the current study coded for the presence of the same six newsworthiness factors: "upstanding accused," "extra violence," "bizarre facts," "multiple parties," "celebrity status," and "cover-up." We chose these six factors based upon their relevance in previous studies of crime reporting. For instance, "upstanding accused" draws from Chermak's [30] conclusion that a defendant's occupation may account for newsworthiness, especially if they are in a position of power or respect in the community. Cheit [23] identifies four other factors that help predict newsworthiness in CSA stories: "extra violence," "bizarre facts," "multiple parties" (victims or defendants), and "celebrity status" (victim or accused). The final factor, "cover-up," was added because it was apparent that many institutional stories were more focused on the scandalous allegations of cover-up than on the underlying abuse. Previous works by Molotch and Lester; Bird; and Altheide and Johnson [34-36] justify the inclusion of this last factor. Finally, we treated each of these newsworthiness factors as a binary. Articles judged to include a characteristic were given a score of "one" for that characteristic; articles not containing the characteristic in question received a score of zero (Table 2).

In order to assess overall segment slant we coded every quotation in each piece. This is the most important variable for our analysis, and was assessed as an integer scale ranging from (-2) to (2), where 


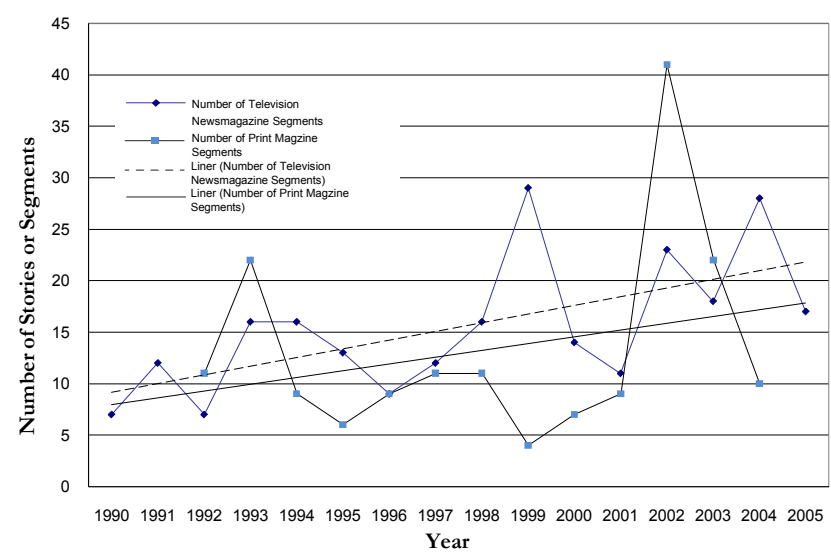

Figure 1: Number of Print Magazine Stories and Television Newsmagazine Segments by Year.

(-2) represents strongly pro-victim stances and (2) indicates strongly pro-accused. We coded quotations with moderate slants as either $(-1)$, moderately pro-victim; or (1), moderately pro-accused. Any statement deemed by be neutral received a score of zero. To account for overall slant associated with each segment, we calculated the overall slant of quotations by averaging the slants of every quotation in the segment.

\section{Findings}

Between the years of 1990 and 2005, television newsmagazines aired 248 segments that were either primarily or exclusively about CSA. There was a moderate positive trend in the number of CSA segments per year. Regression analysis of the number of segments and the broadcast year result in an R-squared of 0.38 and a coefficient of 0.85 (Figure 1), strong evidence that every year saw the airing of almost one additional story. We should also note that these findings differ from the print study, which in spite of finding several spikes in coverage found no overall trend. Interestingly, the television data reveals a large spike in coverage in 1999, the year with the fewest articles in the print newsmagazines. Likewise, the television data do not reveal the same large spikes in CSA coverage that we observe in the print study (1993 and 2002). The year with the fewest television segments is 1990, with only seven being aired; and the year with the most segments is 1999, with twenty-nine segments broadcast. Again, Figure 1 compares the number of television segments per year against the number of print articles, along with regression lines to assist with comparison (Table 3 ).

A strong majority (153 of 248 , or $62 \%$ ) of the total segments are from 48 Hours. After that comes 20/20 with 31 segments (12.5\%), Dateline with 28 (11\%), Primetime with 20 (8\%), Sixty Minutes II with five (2\%), and Turning Point with one (0.4\%). Dateline segments were on average longer than the other shows by over $50 \%$, averaging 5,689 words as compared with the combined average of 3,432 for the rest of the shows. This difference can be accounted for by the flexibility of Dateline's format, which can include both multipart features and full hour documentaries.

\section{Subject}

As we saw with print newsmagazines in the 2010 study, television newsmagazines tend to focus intently upon specific subjects for brief periods of time before they drop them. The "school" subject, for instance, accounts for twelve segments in 1991, 1998, and 1999. After 1999, however, it drops down to three segments a year later, and then two in 2001. Overall, we see that television newsmagazines coverage focuses upon the Michael Jackson controversy extensively, accounting for twenty-five segments on the subject between 2003 and 2005. This is in stark contrast to the medium's coverage of the cover-up within the Catholic Church, which flickers from zero segments in most years to only four in 2002-which is to say, it does not spike at all.

By comparison, our previous study shows exactly the opposite emphasis in print newsmagazines coverage: articles on CSA in the Catholic Church spike in 2002, yet there is comparatively little attention paid to Michael Jackson (four stories in 2003 and one in 2004). Another way to highlight this difference between print and television news media is by examining the overall percentage of news coverage cases occupy in each. In sum, $8.7 \%$ of all the television segments aired in this study were about Michael Jackson, as compared to the observed $4.1 \%$ in print articles. Even more dramatically, while only $3.4 \%$ of television segments addressed the Catholic Church, the subject dominated print articles with an overwhelming $26.2 \%$ of overall CSA print coverage. And again backing up past research on CSA and crime reporting, broader subjects such as "system failure" or "parricide" receive more evenly-if sparse-coverage. For a full breakdown segments by year and subject (Table 4).

\section{Newsworthiness}

As with previous studies on media coverage on CSA [24,26,37], as well as Cheit et al. [2], newsworthiness appears to be an important determinant in story selection. On average, television segments include an average of 3 newsworthiness factors. By way of comparison, this is a higher mean number of newsworthiness factors than print articles (2.27). The frequency distribution of the number of newsworthiness factors for both television and print newsmagazines can be seen in (Figure 2).

Only eleven segments, some of which are repeats, are devoid of newsworthiness factors. Eight of these segments are so-called "bigger picture" stories, dealing with broader subjects rather than specific cases or allegations. One example is the 48 Hours segment "Getting It Right," which addresses the difficulties associated with obtaining accurate testimony from children, and which was repeated three times in our survey sample. These stories have lower than average relevancy scores. It is important to put these findings in context. Such findings are unsurprising: CSA newsworthiness is a function of immediacy and drama [22], which the media more easily convey through specific events-complete with perpetrators and victims-rather than grand "themes." In fact, a previous study shows that $80 \%$ of CSA stories are episodic and only $20 \%$ are thematic [37]. This pattern aligns not only with expectations from past research, but also with the findings of our print analysis. In that study, only four articles had no newsworthiness factors ( $\mathrm{N}=172)$, and they were all "big picture" stories.

\section{Slant}

The present study shows that television newsmagazines offer viewers, on average, slightly pro-victim coverage of CSA stories. In some respects, this average slant is similar to what we observed in the 2010 study. Yet while these slants appear comparable $(-0.46$ for print and -0.40 for television), an examination of their distributions reveals important differences. Overall, the television segments are more polarized than the print articles: there are more segments with extreme slant values of $(-2)$ or (2) than there are with moderate slants (of either-1 or 1). To put it another way, more television segments were either strongly pro-victim or pro-accused than were print articles. This 
Citation: Shavit Y, Weinstein AQ, Reiss-Davis Z, Cheit RE (2014) Television News magazine Coverage of Child Sexual Abuse: 1990-2005. J Mass Communicat Journalism 4: 196. doi:10.4172/2165-7912.1000196

Page 5 of 9

\begin{tabular}{|c|c|c|c|c|c|c|c|c|c|c|c|c|c|c|c|c|c|}
\hline & '90 & ‘91 & '92 & ‘93 & 94 & ‘95 & '96 & ‘97 & 98 & '99 & ‘00 & ‘01 & ‘02 & ‘03 & '04 & ‘05 & Total \\
\hline Bad Samaritan & & & & 1 & 1 & & & & & 2 & 2 & & 1 & & 1 & & 8 \\
\hline Catholic Church & & & & & & & 1 & & & & & & 1 & & & & 2 \\
\hline Celebrities & & & 1 & 1 & 1 & & & & & 2 & & & 2 & & & 1 & 8 \\
\hline Child Custody & & & & & & 1 & & 1 & & & & & 1 & & & 1 & 4 \\
\hline Cover up in Catholic Church & & & 1 & 3 & 1 & & & & & & & & 4 & & & 1 & 10 \\
\hline Cult & & & & & & & & & & 1 & & & 1 & & 3 & 2 & 7 \\
\hline False Accusation & & 1 & 1 & 2 & & & 1 & 1 & 1 & 3 & & & 1 & 1 & 2 & & 14 \\
\hline Famous Cases & 2 & 1 & & 2 & & 1 & & 4 & 4 & 5 & & & & 1 & & & 20 \\
\hline Incest & 1 & 1 & & & & & & & & 1 & & & & & 2 & & 5 \\
\hline Internet & & & & & & & & 1 & & 1 & & & & & 1 & & 3 \\
\hline Legal Responses & 1 & 1 & & 1 & & & 1 & & 1 & & & & & & & & 5 \\
\hline Michael Jackson & & & & & & 1 & & & & & & & & 9 & 9 & 7 & 26 \\
\hline Miscellaneous & & & & & 1 & 3 & 1 & 1 & & 2 & & 5 & 2 & 2 & 2 & 1 & 20 \\
\hline Murder & & & & & & & & & 1 & 2 & & & 1 & 3 & & & 7 \\
\hline Parricide & & & 1 & 4 & 3 & & & & & 1 & 2 & 1 & 3 & & & 1 & 16 \\
\hline Psychology & 2 & 2 & 1 & 2 & 4 & 1 & & & 1 & 1 & 1 & & & & & & 15 \\
\hline Religious, not Catholic & & & 1 & & & & & 1 & & 3 & 3 & 2 & 1 & 1 & 4 & & 16 \\
\hline Running away & & & & & & & & & 2 & 1 & & & & 1 & & 1 & 5 \\
\hline School & & 4 & & & 2 & 1 & & & 4 & 4 & 3 & 2 & 2 & & 1 & & 23 \\
\hline System Failure & 1 & 2 & 1 & & 3 & 5 & 5 & 1 & 2 & 2 & 3 & 1 & 3 & & 3 & 2 & 34 \\
\hline Total & 12 & 12 & 7 & 16 & 16 & 13 & 9 & 12 & 16 & 29 & 14 & 11 & 23 & 18 & 28 & 17 & 248 \\
\hline
\end{tabular}

Table 4: Subjects Covered by Television Newsmagazines by Year.

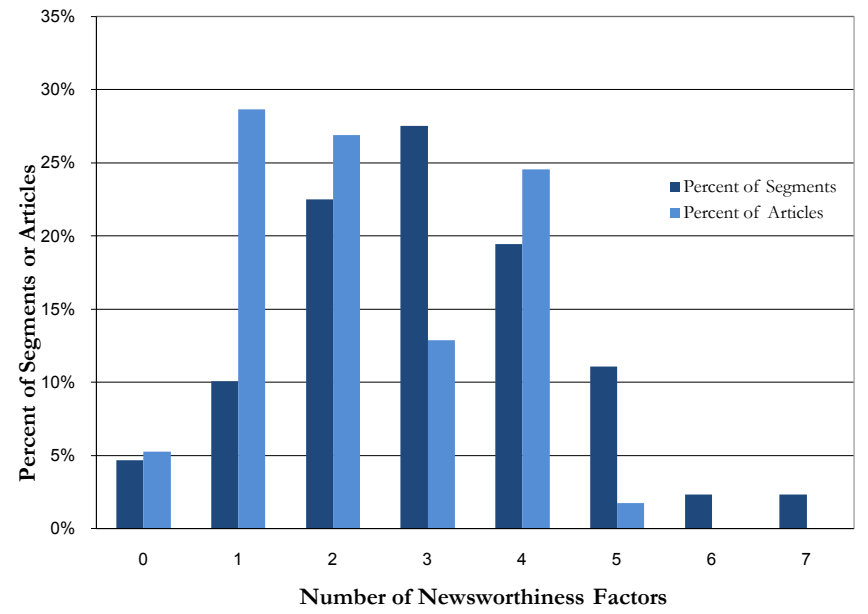

Figure 2: Frequency Distribution of Number of Newsworthiness Factors per TV Newsmagazines Segment and Print Magazine Article.

is in contrast to the print dataset, in which moderately pro-victim $(-1)$ was the most common slant, followed by strongly pro-victim (-2), and then finally by moderately pro-accused (1). The least common slant value for print stories is (2). A graph of this distribution can be seen in (Figure 3).

We additionally found that the relationship between slant and newsworthiness factors in television newsmagazines is much the same as the relationship we found in print newsmagazines. For example, the current study shows that television newsmagazines with an "extra violence" identifier depict victims quite favorably, with an average slant of (-1.11). We compare this to print newsmagazines stories with "extra violence," which was also moderately pro-victim; though not quite to the same extent (they exhibit an average slant of -0.92). Other examples of television newsworthiness factors with relatively pro-victim slants include "stranger danger" (-1.36), "celebrity victim" (-1.00), and "cover-up" (-1.73). In the present study, only "celebrity accused" $(-0.03)$ exhibits a neutral slant, and only "upstanding accused" (0.42) comes close to a moderately pro-accused slant.

Further confirming past findings from the 2010 study, we observe a strong correlation between subject and slant in the television data. Which is to say: some stories tend to be always pro-victim or always pro-accused. Again, while the television slant variable $(-0.40)$ indicates between a neutral and moderately pro-victim slant, this differs by story. Child custody segments, for instance, all have an average slant of strongly pro-accused (2). In other words, each of the four segments on the topic portrays the alleged abuser as the true victim. The ten stories about the Catholic Church cover-up, alternatively, have a slant of (-2), indicating a strong pro-victim slant. This compares to a slant of $(-0.76)$ for the same subject in the print study, indicating that television newsmagazines offered viewers-on average-coverage that was more sympathetic to Church abuse victims than did print newsmagazines. More generally, this suggests that television newsmagazines viewers may receive more polarizing coverage on various subjects than do readers of print newsmagazines.

\section{Anchor comparison}

While so far a comparison between print and television media proves fruitful, we acknowledge that print and television are fundamentally different media. So whereas the print study revealed systematic bias across publications, our attempts to uncover the same biases in television newsmagazines did not provide statistically significant results. Variances between the two media forms directed our inquiries elsewhere for the sources of difference in slant. We considered performing an analysis by television station, but discarded this idea because each show has its own production staff that acts independently of the station as a whole. Instead, we chose to examine the people who have editorial control in television newsmagazines: the anchors. Specifically, we chose to analyze slant in the segments presented by the three anchors most prevalent in our dataset: Dan Rather (43 segments), Stone Phillips (37 segments), and Barbara Walters (28 segments). 


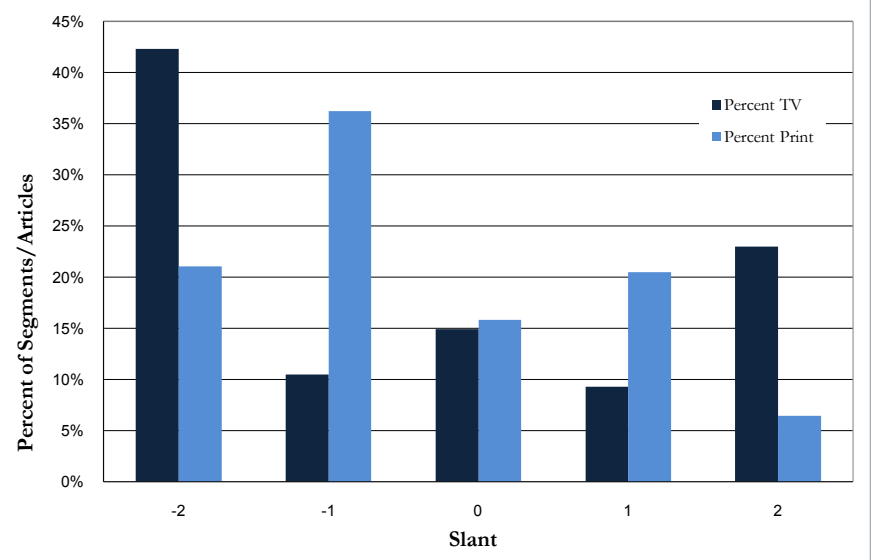

Figure 3: Television and Print Newsmagazines Slant Distributions.

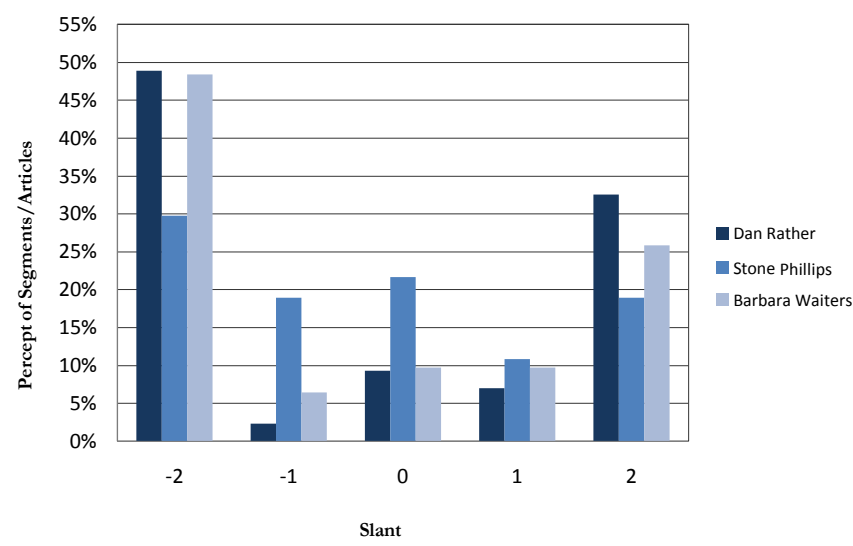

Figure 4: Segment Slant Distributions for Rather, Phillips, and Walters.

We broke slant down by anchor and not by program because some anchors moved between shows. Dan Rather appeared solely on 48 Hours, but Stone Phillips appeared on both 48 Hours and Dateline, and Barbara Walters was on both 48 Hours and 20/20. Rather's segments averaged a slant of $(-0.28)$, Phillips's average was $(-0.30)$, and Walters's was $(-0.42)$. While these mean slants look at first relatively similar, the distribution varies substantially, as we can see in (Figure 4).

Of the three anchors we compared, Dan Rather has the most polarized slant distribution: $81.4 \%$ of his segments have slants of either strongly pro-victim (-2) or pro-accused (2). By contrast, only $48.7 \%$ of Stone Phillips's segments exhibit the most extreme slants. Barbara Walters comes in between Rather and Phillips (though closer to Rather), with $74.2 \%$ of her segments at the poles.

The present analysis also reveals that each of these anchors exhibits preferences for different subjects. For instance, Rather anchors eleven stories on the subject of "school" in our dataset, while Walters only anchors two and Phillips ignores the subject completely. On the other hand, Phillips anchors eleven segments on Michael Jackson, while Walters anchors only four, and Rather does not anchor any. The trends in subjects covered by each anchor can be seen in (Table 5).

\section{Discussion}

The results of this study affirm established theories of newsworthiness, specifically why specific stories are covered, explanations for the extent of coverage, and whether there is change in coverage over time. Furthermore, they offer still more verification of conclusions reached in the previous print study, Cheit et al. [2]. To an even greater extent than print media, television newsmagazines run segments on stories that typify the "newsworthiness" standard in news, with most segments containing more than one such factor. Certain newsworthiness factors, such as the presence of extra violence, are especially prevalent in television segments.

The data indicate the presence of specific "clusters" during certain years. Interestingly, however, the clusters we observe in the television study do not correspond with those exhibited in the print study. While one of the most substantial clusters in the television dataset is the Michael Jackson subject (2003-2005), this subject receives relatively little attention in print newsmagazines.

The overall clustering trend may support the idea that stories are chosen based on "consonance" or "salience" factors and that stories that fit well with prior news themes tend to be reported more often $[18,30]$. Additionally, the presence of subject "clusters" may be the result of newsmagazines' need to expand the definition of CSA in order to keep the reporting on such issues "fresh" and therefore avoid "CSA fatigue" [22]. Both print and television news media operate under the same norms of immediacy and drama, and know that stories that become familiar lose popularity. Once a new CSA subject has reached a saturation point, its coverage decreases and different subjects become popular [24].

Yet the present study uncovers a different pattern of subject clusters in television newsmagazines than we observe in print coverage. This points to potential differences between the media formats. Stories detailing abuse within the Catholic Church were largely based on legal documents and testimonies. While this provides rich material for use in print stories, it provides much less substance for television stories that rely on the availability of visual images and interviews. Michael Jackson, on the other hand, is the very definition of a photogenic celebrity. And in addition to the built in visuals of the Jackson case,

\begin{tabular}{|c|c|c|c|c|}
\hline & Rather & Phillips & Walters & Total \\
\hline \multicolumn{5}{|l|}{ Subject } \\
\hline Bad Samaritan & - & - & 1 & 1 \\
\hline Catholic Church & - & - & - & 0 \\
\hline Celebrities & - & 1 & - & 1 \\
\hline Child Custody & 1 & 1 & - & 2 \\
\hline Cover-up in Catholic Church & 1 & 1 & - & 2 \\
\hline Cult & - & 4 & 1 & 5 \\
\hline False Accusation & 5 & - & 3 & 8 \\
\hline Famous Cases & 8 & 3 & - & 11 \\
\hline Incest & 1 & - & - & 1 \\
\hline Internet & - & 1 & 2 & 3 \\
\hline Legal Responses & 1 & - & - & 1 \\
\hline Michael Jackson & - & 11 & 4 & 15 \\
\hline Miscellaneous & - & 2 & 3 & 5 \\
\hline Murder & - & 2 & 1 & 3 \\
\hline Parricide & 2 & 2 & 4 & 8 \\
\hline Psychology & 4 & - & 3 & 7 \\
\hline Religious, Not Catholic & 2 & 4 & - & 6 \\
\hline Running Away & - & 1 & - & 1 \\
\hline School & 11 & - & 2 & 13 \\
\hline System Failure & 7 & 4 & 7 & 17 \\
\hline Total & 43 & 36 & 31 & 110 \\
\hline
\end{tabular}

Table 5: Television Newsmagazines Anchors and CSA Subject Coverage. 
the accused's popularity as a musician added an auditory dimension to coverage that print media were altogether unable to present. Then there are also Jackson's personal eccentricities (a pet chimpanzee, or his Neverland Ranch) adding "bizarre facts" that further drew the public's attention [26]. Regarding print materials, however, there was only so much new information with which editors could work.

To test the assertion that print magazines covered the Church and television focused on Michael Jackson we performed a LexisNexis search of both subjects in the fifteen highest circulated daily newspapers in the country as well as the major network news outlets (Appendix 2). This survey confirms that CSA in the Catholic Church was reported more frequently in newspapers than television news, while Michael Jackson was covered more regularly in television news than print. It may lend credence to the idea that differences in coverage of these subjects has more to do with the differences between visual and print media than with editorial decisions specific to the newsmagazines format.

As with the print study, our findings here indicate that slant operates systematically throughout television newsmagazines. While this trend manifests itself in statistically significant differences between average slants in each publication in the print study, in the television study it is visible as notably different slant distributions between different anchors.

\section{Slant and Cycles}

Generally, television segments and print articles have similar average slants $(-0.46$ for print and -0.40 for television). Overall, however, the television segments are more polarized than print articles. The presence of an average neutral slant despite the predominance of polarized individual story slants confirms crime-reporting theories. Although there is disagreement in the literature regarding the source of bias in crime coverage, it is widely agreed that news stories are often slanted in their representation of crime. Ericson et al. [38], however, find that while specific stories tend to have explicit ideological slants, the overall slant of news outlets' coverage of specific issues is generally more evenhanded. Our original print study provided support for both of these theories and this study reaffirms these findings.

Our original study of print newsmagazines found that different outlets exhibit unique slant distributions in their coverage of CSA stories. Yet the present study does not identify statistically significant differences in slant between individual newsmagazines. We attribute this null finding to the prominence of 48 Hours (a newsmagazines for which several anchors authored segments, and therefore had inconstant editorial control) in our dataset. Instead, we studied the three anchors appearing most frequently in our dataset, finding significant differences in anchor slant. In conjunction with our finding that the anchors favor different subjects, these findings confirm a fair amount of editorial control over the way in which CSA is described. As Comstock [39] details, news is often framed in many different ways based on the discretion of the anchor relaying the story: "television news depends on events but is constructed in accord with the vision of news-people" [40].

This study also confirms one of the more surprising findings in Cheit et al. [2] regarding slant periodicity. The crime reporting literature maintains that the slant of a specific issue's coverage shifts once the issue has become familiar, and once new claims-makers have had time to organize and expound their views [41]. Based on this theory, one could expect overall segment slant to shift in a cyclical nature between pro-victim and pro-accused. Beckett [29] points to just such a backlash against the victims, for instance the rise of false-memory and false accusation cases in the early 1990s, as a sign that this trend holds for CSA coverage. Yet in neither the present study nor the 2010 study on print news do we observe such a shift in overall slant.

Two important findings may explain the absence of this anticipated slant: the episodic nature of specific coverage, and the inconsistent frequency of CSA coverage in general. The data support our previous findings that changes in subject occur in a largely episodic fashion. This finding further contradicts Beckett's [29] explanation of changes in CSA representations as "waves of claims-making." In the print study, the most prominent example occurs in 2002, when stories with the subject "Cover-up in Catholic Church" rise from zero to 40 and then drop back to zero by 2004 . While the television data do not include such a dramatic spike, they nonetheless reveal the same episodic trend in coverage. The "school" subject jumps from zero to twelve in 1998 and 1999, and drops back down to three the following year. Similarly, in 2003 the Michael Jackson subject rises from zero to nine. As with the previous study, this study confirms there is a strong correlation between an article's subject and its slant, and that there is no shift in slant per subject over time.

\section{Limitations}

The results presented above are subject to some limitations. First, for the sake of comparability with our findings regarding print newsmagazines, we limit our analysis of television segments to the content of transcripts. This clearly fails to account for the influence of the visual and auditory elements of programs like 60 minutes on viewers [42]. Future in depth studies of television CSA coverage should consider all of these elements, particularly in light of the emotive power of visual media [32]. This will undoubtedly matter, especially when the image is of an abused child or a sympathetic accused. A second limitation stems from the decreasing importance of both print and television media as a news source. For instance, a recent Pew Study [43] suggests that television newsmagazines are more popular among older Americans than younger cohorts. And a chart of Nielsen ratings indicates that evening news viewership, which like television newsmagazines is watched primarily in primetime, is on the decline [44]. Studies of future time periods should consider the impacts of the blogosphere and online reporting on public perceptions of CSA.

A third limitation is that while our method to assess the slant of coverage has the advantage that our results are consistent across researchers, it undoubtedly oversimplifies an important variable. Reducing the analysis of slant to a simple scale (strongly pro-victim to strongly-pro accused) misses detail about the complexity of stories that represent multiple frames. The scale developed from the previous study, and implemented again here, might also over-interpret CSA stories into criminal justice terms, where these dichotomous labels fit best. Future research that aims to analyze CSA outside of the criminal justice context may not find our scale as useful as others.

\section{Conclusions}

In their media study, Newport and Saad [45] cite a Gallup poll finding that "primetime TV newsmagazines are both popular and highly trusted." While the popularity of these sources has decreased in the past decade, they remain important sources of information regarding social phenomena such as child abuse. What McManus and Dorfman [27] claim about newspapers at the turn of the 20th century, we say is true of television newsmagazines today: they are standard bearers of "what's news." Findings from both our print and television 
studies indicate that the drive to represent "newsworthy" instances of CSA pushes coverage toward sensational cases, overemphasizing "stranger danger" as a social concern and underemphasizing more common cases of intra-familial offenders and incest.

These patterns of misinformation are of more than scholarly interest: they have real, tangible effects upon peoples lives. Take for instance the media's suggestion that CSA generally occurs in remarkable and bizarre contexts, at the hands of strangers in public places-rather than at the hands of relatives, family friends, or acquaintances. Sample et al. [46] illustrate how these common CSA myths influence policymakers who are, themselves, part of the viewing public. The results have public health implications. We not only get policies aimed at strangers rather than offenders known to the victim, and therefore ill designed to address the vast majority of CSA incidents $[20,47]$, but laws that actually may ostracize past offenders and increase rates of recidivism $[48,49]$. In addition to the effects upon policy-makers, it is suggested that media coverage of CSA may affect implementation of those same laws, for instance by biasing jurors in criminal cases [50]. And some researchers even exhort the news media to be cognizant of how they present the news, not just what they present. Focusing upon "episodes" of CSA, the media paint an unsystematic picture to the public, where crime is the result of personal action and not systemic malfunction. Our point is simple: those we think of as the "viewing public" is more than simply our neighbors. They are our police officers, jurors, and legislators.

What can the media do to correct the dangers we have identified? One solution is to acknowledge the significant control that editors and anchors possess in framing the stories they report. By focusing upon cases of intra-familial abuse, both incest and abuse by people known to the victim, the news media can better educate the public to the real dangers of CSA. This means a closer relationship between media and experts $[14,51]$ : both should reach out to help the other correct the current imbalances in reporting. Additionally, the news media (especially television) could better moderate their polarized coverage that artificially depicts CSA as a "black and white" issue. Such polarized portrayals may even lead to the exact opposite reactions that journalists hope to elicit. In other words media effects may not be equal across an audience. One recent study shows that Catholics became more supportive (i.e. less critical) of the Church in the wake of media stories focusing upon priest sex abuse [52]. The media's power, then, is a double-edged sword: it is a powerful tool that sometimes cuts in the direction the media want, and sometimes in the other direction. But it cuts nonetheless.

What will happen as newsgathering trends more toward "crowd sourcing" and away from established sources like Walters, Phillips, and Rather? One sees at least two alternatives. The first is that CSA coverage may be freed from the domination of male $[24,53]$ voices, and therefore paint a more realistic picture of CSA dangers. The other is that existent myth may reverberate in an unchecked, online echo chamber. Cromer et al.'s [54] study demonstrates the prevalence of myths online, gesturing toward this possible outcome. Of course these are not mutually exclusive possibilities, and only time will tell which (if either) predominates. What is clear is that whether in the form of print, television, or online journalism, the media will play an integral role moving forward. We believe that the type of longitudinal analysis undertaken in this study may provide a useful mechanism for understanding the nature of information out there for public consumption.

\section{References}

1. Sapp MVCheit RE, Shavit Y, Reiss-Davis Z (2010) Magazine Coverage of Child Sexual Abuse, 1992-2004. Journal of Child Sexual Abuse 19: 99-117.

2. Downs A (1957) An Economic Theory of Democracy. New York: Harper \& Row.

3. Iyengar S (1991) Is Anyone Responsible? How Television Frames Political Issues. Chicago: The University of Chicago Press.

4. lyengar S, Kinder DR (2010) News That Matters: Television and American Opinion, Updated Ed. Chicago: The University of Chicago Press.

5. McCombs M, Reynolds A (2002) News Influence on Our Pictures of the World. Media Effects: Advances in Theory and Research, Second Ed.

6. Scheufel D, Tewksbury D (2007) Framing, Agenda Setting, and Priming: the Evolution of three Media Effects Models. Journal of Communication 57: 9-20.

7. Lester M (1980) Generating Newsworthiness: The Interpretive Construction of Public Events. American Sociological Review 45: 984-994.

8. Dominick JR (1978) Crime and Law Enforcement in the Mass Media. Winnick, Deviance and the Mass Media.

9. Sherizen S (1978) Social Creation of Crime News: All the News Fitted to Print Deviance and the Mass Media.

10. Bolen RM (2001) Childhood Sexual Abuse: Its Scope and Our Failure. Springer.

11. Davidson JC (2008) Child Sexual Abuse: Media Representation and Government Reactions. New York: Routledge-Cavendish.

12. Lichtenberg J, MacLean D (1991) The Role of the Media in Risk Communication. Communicating Risks to the Public: International Perspectives.

13. Lawrence R, Mueller D (2003) School Shootings and the Man-Bites-Dog Criterion of Newsworthiness. Youth Violence and Juvenile Justice 1: 330-345.

14. Roshier B (1981) The selection of crime news by the press. The manufacture of news: Social problems, deviance and the mass media.

15. Chibnall S (1977) Law and order news: An Analysis of Crime Reporting in the British Press London: Tavistock.

16. Jerin R, Fields C (1994) Murder and mayhem in USA Today: A quantitative analysis of the national reporting of states' news. Media, Process and the Social Construction of Crime: Studies in Newsmaking Criminology.

17. Surette R (1998) Media, crime, and criminal justice: Images and realities. Belmont, CA: West/Wadsworth.

18. Best J (1999) Random Violence: How We Talk about New Crimes and New Victims. Berkeley: University of California Press.

19. Kemshall H, Wood J (2008) Risk and Public Protection: Responding to Involuntary and 'Taboo' Risk. Social Policy \& Administration 42: 611-629.

20. Pirkis J, Burgess P, Blood RW, Francis C (2007) The Newsworthiness of Suicide. Suicide Life Threat Behav 37: 278-283.

21. Skidmore $P$ (1995) Telling tales: Media power, ideology and the reporting of child sexual abuse in Britain. Crime and the media: The post-modern spectacle.

22. Cheit RE (2003) What hysteria? A systematic study of newspaper coverage of accused child molesters. Child Abuse \& Neglect 27: 607-623.

23. Kitzinger J, Skidmore $P$ (1995) Playing safe: Media coverage of child sexual abuse prevention strategies. Child Abuse Review 4: 47-56.

24. Kitzinger J (1999) Researching Risk and the Media. Health, Risk \& Society 1 : 55-69.

25. Kitzinger J (2004) Framing Abuse: Media Influence and Public Understanding of Sexual Violence Against Children. Pluto Press.

26. McManus J, Dorfman L (2002) Youth Violence Stories Focus on Events, Not Causes. Newspaper Research Journal 23: 6-20.

27. Wilczynski A, Sinclair K (1999) Moral tales: Representations of child abuse in the quality and tabloid media. The Australian and New Zealand Journal of Criminology 32: 262-283.

28. Beckett K (1996) Culture and the politics of signification: The case of child sexual abuse. Social Problems 43: 57-76. 
Citation: Shavit Y, Weinstein AQ, Reiss-Davis Z, Cheit RE (2014) Television News magazine Coverage of Child Sexual Abuse: 1990-2005. J Mass Communicat Journalism 4: 196. doi:10.4172/2165-7912.1000196

Page 9 of 9

29. Chermak S (1995) Victims in the news: Crime and the American news media. Boulder, CO: Westview Press.

30. Pew Research (2008) Project for Excellence in Journalism. The State of the News Media: Newsmagazines.

31. Mutz DC, Reeves B (2005) The New Videomalaise: Effects of Televised Incivility on Political Trust. The American Political Science Review 99: 1-15.

32. Rivers WR (1970) Appraising Press Coverage of Politics. Politics \& the Press.

33. Molotch H, Lester M (1974) News as Purposive Behavior: On the Strategic Use of Routine Events, Accidents, and Scandals. American Sociological Review 39: 101-112.

34. Bird E (2003) The audience in everyday life: Living in a media world. New York Routledge.

35. Altheide DL, Johnson JM (2012) Normal Crimes at Penn State. Cultural Studies <=> Critical Methodologies 12: 306-308.

36. Mejia P, Cheyne A, Dorfman L (2012) News Coverage of Child Sexual Abuse and Prevention, 2007-2009. Journal of Child Sexual Abuse 21: 470-487.

37. Ericson RV, Baranek PM, Chan JBL (1991) Representing Order: Crime, Law and Justice in the News Media. Toronto: University of Toronto Press.

38. Comstoc kG (1991) Television in America, Second Ed. Newbury Park, CA: Sage.

39. Clayman SE, Reisner A (1998) Gatekeeping in Action: Editorial Conferences and Assessments of Newsworthiness. American Sociological Review 63: 178199.

40. Best J (1990) Threatened children: Rhetoric and concern about child-victims Chicago: University of Chicago Press.

41. Bryski Bruce G (1988) The Rhetoric of Television News: "60 Minutes" as Media Persuasion. The Pennsylvania State University.
42. Pew Research (2010) Ideological News Sources: Who Watches and Why. The Pew Research Center for The People \& The Press.

43. Pew Research (2013). Evening News Viewership over Time.

44. Newport F, Saad L (1998) A Matter of Trust. American Journalism Review.

45. Sample LL, Kadleck C (2008) Sex Offender Laws: Legislators' Accounts of the Need for Policy. Criminal Justice Policy Review 19: 40-62.

46. Meloy ML, Miller SL, Curtis KM (2008) Making Sense out of Nonsense: The Deconstruction of State-Level Sex Offender Residence Restrictions. American Journal of Criminal Justice 33: 209-222.

47. Comartin EB, Kernsmith PD, Kernsmith RM (2009) Sanctions for Sex Offenders: Fear and Public Policy. Journal of Offender Rehabilitation 48: 605-619.

48. Mustaine EM, Tewksbury R (2011) Residential Relegation of Registered Sex Offenders. American Journal of Criminal Justice 36: 44-57.

49. Klein JL, Tolson D, Longo LM (2013) Pretrial Publicity and Pedophilia: A Content Analysis of the Jerry Sandusky Case. Justice Policy Journal 10: 1-26.

50. Woody JD (2002) Media Coverage of Child Sexual Abuse: An Opportunity for Family Therapists to Help Families and Communities. The Journal of Family Therapy 30: 417-426.

51. Mancini C Shields RT (2014) Notes on a (Crime) Scandal: The Impact of Media Coverage of Sexual Abuse in the Catholic Church on Public Opinion. Journal of Criminal Justice 42: 221-232.

52. Harris RJ, Scott CL (2002) The Effects of Sex in the Media. Media Effects Advances in Theory and Research, Second Ed.

53. Cromer LD, Goldsmith RE (2010) Child Sexual Abuse Myths: Attitudes, Beliefs and Individual Differences. J Child Sex Abus 19: 618-647.

54. Vandeven AM (2005) Update on Childhood Sexual Abuse. Curr Opin Pediatr 17: $258-264$ 